\title{
COMMENTARY
}

\section{Initiation of renal replacement therapy: is timing everything?}

\author{
Catherine SC Bouman*1 and Lui G Forni ${ }^{2}$ \\ See related research by Ostermann and Chang, http://ccforum.com/content/13/6/R175
}

\begin{abstract}
Acute kidney injury is commonly encountered and in the critically ill treatment is principally supportive. A recent large, multicentre study has used retrospective analysis to try and identify patient outcomes when commencing renal replacement therapy using conventional biochemical and physiological markers. The authors have also made an attempt to decipher when to commence renal replacement therapy.
\end{abstract}

Acute kidney injury (AKI) remains a commonly encountered medical problem, often finding its way to the intensive care unit (ICU). Treatment involves normalisation of the circulation, and, failing that, renal replacement therapy (RRT) of whatever type.

The interesting paper by Ostermann and Chang describes the correlation between parameters at initiation of RRT and outcome in critically ill patients who underwent RRT [1]. Although the study is retrospective, it is however multicentred and includes a large number of patients. ICU survivors (55.9\%) were significantly younger, and less sick with less pre-existing chronic illnesses. In a multivariate analysis, mechanical ventilation and associated neurological failure on the day of RRT were the strongest independent risk factors for mortality, followed by hepatic, gastrointestinal and haematological failure, and pre-existing health problems. A higher serum $\mathrm{pH}$ was independently associated with a better outcome. A raised urea and a low creatinine concentration at initiation of RRT were independent risk factors for dying. Similar risk factors for death from AKI have been identified in the past, albeit at a single centre and

\footnotetext{
*Correspondence: c.s.bouman@amc.uva.nl

'Department of Intensive Care, Academic Medical Center, University of Amsterdam, PO Box 22660, 1100 DD Amsterdam, the Netherlands

Full list of author information is available at the end of the article
}

including fewer patients [2,3]. Moreover, the data share similarities with several subsequent scoring systems for AKI - namely, age, need for ventilation, oligo-anuria, liver dysfunction and acidosis $[4,5]$.

What should be borne in mind is that the data analysed are somewhat old, and that over this period there have been several changes in the ICU practice for RRT: not least in the choice of replacement fluid and the dosing of RRT. Bicarbonate-buffered haemofiltration was not described until 1991 and was not commercially available until the late 1990s. In addition, dosing of RRT has gradually increased during the past decade, and it is likely in the present study that the dose may have been inadequate, particularly in the patients receiving continuous arteriovenous techniques. Using the current buffering techniques and RRT dose, therefore, the observed effects on acid-base parameters may not be so marked.

In medicine, much like politics, one of the essential ingredients is timing; however, there is only a small evidence base regarding the time to initiate RRT in AKI [6]. In Ostermann and Chang's study, mortality was significantly lower when RRT was started before the AKI stage III creatinine criteria were fulfilled (serum creatinine $\leq 354 \mu \mathrm{mol} / \mathrm{l}$ or a rise in serum creatinine by $>300 \%$ from baseline), and also when RRT was started $<3$ days after ICU admission [1]. Although these findings may suggest that early initiation of RRT is beneficial, the retrospective design of this study does not allow definitive conclusions that may directly influence practice to be drawn. Only one randomised controlled trial has so far investigated whether the timing of RRT improves outcome in a mixed ICU population with AKI, and the results were inconclusive [7]. A recent systematic review identified 23 studies on the timing of RRT, including 10 studies more than 30 years ago, and a subsequent meta-analysis suggested that early initiation of RRT may improve outcome [8]. The methodological quality of the trials favouring early timing is poor, however, and the studies cannot be sensibly combined in a meta-analysis because of the heterogeneity in the definitions of timing, study populations and RRT techniques. 
Several important questions therefore remain when considering RRT for AKI - namely, when to start treatment, how long to continue treatment and, to a degree, how much treatment to give. The answers to these questions will probably involve not only renal criteria, but also the severity of other organ failure(s). Although we do need properly designed randomised controlled trials to answer these questions, the identification of risk factors for death following AKI may help in the design of future studies as well as, perhaps, the use of biomarkers. The conventional renal criteria (creatinine and diuresis) are a poor reflection of AKI and do not differentiate between pre-renal failure and intrinsic renal damage. Early initiation of RRT in pre-renal failure is probably less important given that it is likely to recover after resuscitation of the circulation. If AKI is the result of cellular injury due to ischemia, reperfusion, inflammation or oxidant stress, however, early initiation may mitigate further damage. The use of biomarkers may prove helpful to detect AKI at an early stage, to differentiate pre-renal failure from AKI, and to decide when to start or stop RRT [9]. We shall have to wait and see.

\section{Abbreviations}

$A K I=$ acute kidney injury; $I C U$ = intensive care unit; $R R T=$ renal replacement therapy.

\section{Author details}

'Department of Intensive Care, Academic Medical Center, University of Amsterdam, PO Box 22660, 1100 DD Amsterdam, the Netherlands

${ }^{2}$ Department of Critical Care, Western Sussex Hospitals Trust, Brighton \& Sussex Medical Schools, University of Sussex, Brighton, East Sussex BN1 9PX, UK

\section{Competing interests}

The authors declare that they have no competing interests.

Published: 10 February 2010

\section{References}

1. Ostermann M, Chang R: Correlation between parameters at initiation of renal replacement therapy and outcome in patients with acute kidney injury. Crit Care 2009, 13:R175.

2. Barton IK, Hilton PJ, Taub NA, Warburton FG, Swan AV, Dwight J, Mason JC: Acute renal failure treated by haemofiltration: factors affecting outcome. Q J Med 1993, 86:81-90.

3. Forni LG, Wright DA, Hilton PJ, Carr P, Taub HA, Warburton F: Prognostic stratification in acute renal failure. Arch Intern Med 1996, 156:1023-1027.

4. Mehta RL, Pascual MT, Gruta CG, Zhuang S, Chertow GM: Refining predictive models in critically ill patients with acute renal failure. J Am Soc Nephrol 2002, 13:1350-1357.

5. Uchino S, Bellomo R, Morimatsu H, Morgera S, Schetz M, Tan I, Bouman CSC, Macedo E, Gibney N, Tolwani A, Doig GS, Oudemans-van Straaten HM, Ronco C, Kellum JA: External validation of severity scoring systems for acute renal failure using a multinational database. Crit Care Med 2005, 33:1961-1967.

6. Bouman CS, Oudemans-van Straaten HM: Timing of renal replacement therapy in critically ill patients with acute kidney injury. Curr Opin Crit Care 2007, 13:656-661.

7. Bouman CS, Oudemans-van Straaten HM, Tijssen JG, Zandstra DF, Kesecioglu $\mathrm{J}$ : Effects of early high-volume continuous venovenous hemofiltration on survival and recovery of renal function in intensive care patients with acute renal failure: a prospective, randomized trial. Crit Care Med 2002 30:2205-2211

8. Seabra VF, Balk EM, Liangos O, Sosa MA, Cendoroglo M, Jaber BL: Timing of renal replacement therapy initiation in acute renal failure: a meta-analysis. Am J Kidney Dis 2008, 52:272-284.

9. Endre $\mathrm{ZH}$, Westhuyzen J: Early detection of acute kidney injury: emerging new biomarkers. Nephrology (Carlton) 2008, 13:91-98.

doi: $10.1186 / \mathrm{cc} 8188$

Cite this article as: Bouman CSC, Forni LG: Initiation of renal replacement therapy: is timing everything? Critical Care 2010, 14:107. 